\title{
The effect of prey availability on ovarian development and oosorption in the ladybird beetle Harmonia axyridis (Coleoptera: Coccinellidae)
}

\author{
NAOYA OSAWA \\ Laboratory of Forest Ecology, Graduate School of Agriculture, Kyoto University, 606-8502 Kyoto, Japan; \\ e-mail: osawa@kais.kyoto-u.ac.jp
}

Key words. Asymmetry, Harmonia axyridis, Coccinellidae, energy storage, oosorption, ovarian development, oviposition strategy, population dynamics, predator

\begin{abstract}
The ladybird beetle Harmonia axyridis Pallas was investigated under laboratory conditions to clarify the relationship between food abundance or scarcity and ovarian development or oosorption. Four conditions were used: (1) fully fed for $24 \mathrm{~h},(2)$ 24-h starvation, (3) 48-h starvation, and (4) 24 -h starvation followed by $24-\mathrm{h}$ re-feeding. Body length and initial body weight were not significantly related to the number of ovarioles per female. Both starvation conditions significantly increased the percentage of oosorptive individuals and ovarioles per female, and significantly decreased the percentage of mature ovarioles per female. Refeeding for $24 \mathrm{~h}$ after a 24-h starvation resulted in a significantly higher percentage of mature ovarioles per female; however, the percentage of mature ovarioles remained lower than in the fully fed condition. Oosorption mainly occurred during the intermediate developmental stage of the ovarioles. The rates of ovarian development and oosorption in predatory $H$. axyridis were much faster compared with those in herbivorous ladybird beetles. Body length, initial body weight, and the number of ovarioles were significantly correlated with the number of eggs laid during the last $24 \mathrm{~h}$ of each experimental condition. From an analysis of the weight loss and the number of eggs laid during the last $24 \mathrm{~h}$ of each experimental condition, it appears that the realized weight of the eggs may be directly determined by the amount of food digested by the adult. The ovarian development and oosorption were asymmetric in the right and left ovaries. These may be important strategies for oviposition in H. axyridis, because selective provision of maturing ovarioles in the right or left ovary with digested nutrients would favor their development. In addition, the energy loss through oosorption during the intermediate developmental stage of oocytes would be less than the energy loss resulting from the resorption of mature oocytes. Therefore, one role of the ovary in H. axyridis, in addition to egg production, might be as a kind of energy storage system for increasing reproductive success. An immediate start of ovarian development under favorable feeding conditions and rapid oosorption during food scarcities may be an adaptive ovipositional and survival strategy for female adults of $H$. axyridis in response to heterogeneous and fluctuating resource conditions.
\end{abstract}

\section{INTRODUCTION}

One of many survival adaptations in animals is a strategy for reproduction which conserves resources and insures reproductive success (e.g., Bell \& Bohm, 1975; Büning, 1994). A major reason for the success of arthropods has been the evolution of specialized ovaries and vitellogenic mechanisms that enable them to produce, sometimes in a single day, an egg mass exceeding half their body mass (e.g., Eckelbarger, 1994). Ovarian development is itself under selection pressure and is conceivably dynamic in ways that permit insects to cope with variations in host and food resources (e.g., Papaj, 2000). Thus, many insects develop ovaries and lay eggs only when in suitable habitats. In contrast, resorption of oocytes (oosorption) is also a widespread phenomenon that has been recorded in many orders of Insecta (e.g., Chapman, 1998). Oosorption occurs instead of oviposition in response to behavioral, ecological, or physiological factors, e.g., nutritional deficiency, virginity, social pressure, lack of ovipositional sites, or parasitism. Oosorption is thus thought to be a specific adaptive reproductive strategy in insects (Bell \& Bohm, 1975).

In many insect taxa, starvation plays an important role in the induction of oosorption (e.g., Kurihara, 1975; Perez-Mendoza et al., 2004). Many histological and histo- chemical observations have shown that follicular cells stop producing yolk protein precursors during oosorption and resorb the ooplasm through phagocytic activity (e.g., Wilde, 1964; Maeta \& Kurihara, 1971; Kurihara, 1975, 1981). Juvenile hormone is generally involved in the control of yolk accumulation in the oocytes, and the lack of this hormone is associated with oosorption (Chapman, 1998). The adaptive significance of oosorption in the herbivorous ladybird beetle Epilachna niponica has been well documented through intensive field and laboratory experiments focusing on the reproductive trade-off between oosorption and female survival (Ohgushi \& Sawada, 1985; Ohgushi, 1996). Oosorption is an adaptive response to the absence of food resources, when the increase in the survival of females that is gained by egg resorption enhances the possibility for future oviposition and results in an increase in the lifetime reproductive success of the female (Ohgushi \& Sawada, 1985; Ohgushi, 1996). In the predatory ladybird beetle Harmonia axyridis Pallas, ovarian development may be explained by the evolutionary influence of mating acceptability; ovarian maturity is critically involved in mating receptivity (Obata, 1988). However, ovarian development and oosorption in predatory ladybird beetles have not been 
well investigated from the viewpoint of reproductive success.

The habitats of natural populations of the aphidophagous ladybird beetle $H$. axyridis can be categorized into three types, mainly due to the quality of food: dominant and suitable habitats for food and reproduction (i.e., prey aphid quality is suitable for ovarian development; thereafter female beetles lay eggs at these habitats and the offspring can develop to adulthood), refuge habitats mainly for food (i.e., female beetles eat the prey at these habitats because suitable prey aphids are scarce or absent; however, females do not lay eggs because the prey aphid quality is not suitable for ovarian development), and refuge habitats for food and reproduction (i.e., female beetles eat the prey at these habitats because suitable prey aphids are scarce or absent; thereafter some ovarian development occurs and a few eggs are laid, but the offspring seldom develop to adulthood because prey conditions are poor) (Osawa, 2000). While using heterogeneous habitats with widely fluctuating prey abundance, the beetles arrive at a habitat favorable for oviposition through long- and short-distance movements; female beetles remain in the favorable habitat for a few days before laying their eggs (Osawa, 2000). These resource-tracking behaviors in $H$. axyridis adults imply that (1) the adults of $H$. axyridis might be accustomed to experience alternating periods of extreme satiation and starvation, and (2) the rate of ovarian development and oosorption in $H$. axyridis females might vary in tandem with changes in prey availability. In particular, oosorption might play an important role in supplying the energy required for their resourcetracking activity in heterogeneous habitats if the rate of oosorption tracks the fluctuation of resources. The current study was thus undertaken to investigate the ovarian development and oosorption of the ladybird beetle $H$. axyridis in relation to the presence vs. absence of food.

\section{MATERIAL AND METHODS}

\section{Laboratory experiments}

The experiments were carried out under laboratory conditions at $25^{\circ} \mathrm{C}$ and approximately $70 \%$ relative humidity with a $16 \mathrm{~L}$ : 8D photoperiod, using Harmonia axyridis Pallas collected from the Botanical Gardens of Kyoto University in early May 1994, when $H$. axyridis is reproductively active. For each female beetle, the body length was measured to the nearest $0.01 \mathrm{~mm}$, and the initial, natural body weight was determined. Females were individually reared with a surplus of aphids (Aphis spiraecola Patch, Hemiptera: Aphididae) on a piece of wet filter paper (7 $\mathrm{cm}$ diameter $)$ in a plastic Petri dish $(9 \mathrm{~cm} \times 1.5 \mathrm{~cm})$ with a sprig of Spiraea thunbergii Sieb. (Rosaceae). Fresh shoots of S. thunbergii with aphids were collected daily near the university campus. The shoots were changed daily and the number of eggs was recorded. The body weight of each beetle was recorded daily, and weight losses were recorded as a percentage of initial body weight. At the end of experiment, the ovaries were examined under a stereomicroscope, and the number of ovarioles in the right and left ovaries, the developmental stages of the ovarioles (cf., Obata, 1988), and any evidence of oosorption were recorded (Fig. 1). Oosorption of an ovariole was considered to have occurred if (1) the color of the oosorptive oocyte was dark yellow or orange and/or (2) the shape of the oocyte was modi-

\section{Developmental stages of oocytes in an ovariole}

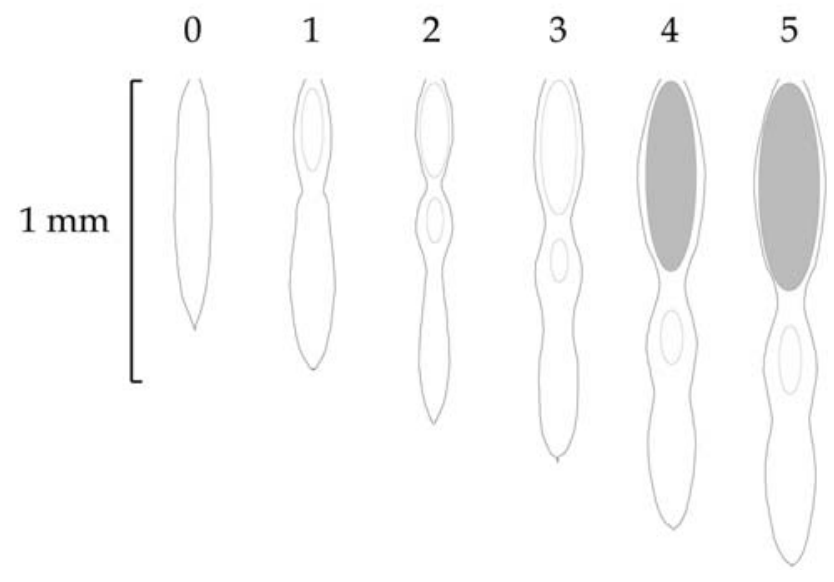

Fig. 1. The developmental stages of oocytes in an ovariole in $H$. axyridis. Dark areas show yellow yolk. Stage 0: no oocyte. Stage 1: one oocyte. Stage 2: two whitish oocytes. Stage 3: two oocytes; the basal one filled with whitish yellow yolk. Stage 4: two oocytes; the basal one filled with yellow yolk. Stage 5: the basal oocyte grows to the maximum size (see Obata, 1988).

fied and the oocyte was smaller than normal oocytes (Fig. 2). Among the six stages of ovariole development, stages 4 and 5 were defined as mature ovarioles.

Four experimental conditions were used to examine the effect of changes in resources on the dynamics of ovarian development and oosorption. Female beetles were raised individually for varying periods of food abundance and starvation, before examination of the ovarioles. Fifteen replicates were used for each condition, as follows.

(1) Fully fed: Each beetle was reared with abundant food (a surplus of aphids) for $24 \mathrm{~h}$, and the ovarioles were then examined, as described above.

(2) 24-h starvation: Abundant food for $24 \mathrm{~h}$, followed by $24 \mathrm{~h}$ without food.

(3) 48-h starvation: Abundant food for $24 \mathrm{~h}$, followed by $48 \mathrm{~h}$ without food.

(4) Re-fed: Abundant food for $24 \mathrm{~h}$, followed by $24 \mathrm{~h}$ without food, and an additional $24 \mathrm{~h}$ with abundant food.

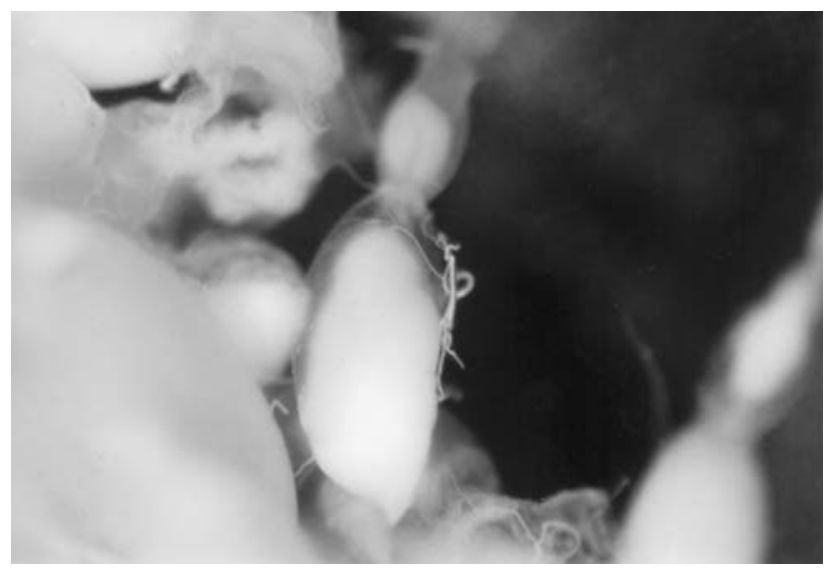

Fig. 2. A photograph of an oosorptive oocyte in an ovariole (center). 


\section{The definition of asymmetry of ovarian development and oosorption}

To analyze the asymmetry of ovarian development and oosorption in the right and left ovaries, the following definitions were established:

The percent asymmetry of the numbers of ovarioles in the right and left ovaries $=\frac{\left|O_{R}-O_{L}\right|}{O_{T}} \times 100$, where $O_{R}$ is the number of ovarioles in the right ovary, $O_{L}$ is the number of ovarioles in the left ovary, and $O_{T}$ is the total number of ovarioles in the right and left ovaries.

The asymmetry of mature and oosorptive ovarioles was calculated in the same way.

\section{Data analysis}

A regression model using standard least-squares analysis for two numerical factors and their interaction was applied to the number of ovarioles; a regression model using standard leastsquares analysis for three numerical factors and their interactions was applied to the number of eggs laid during the last $24 \mathrm{~h}$ of each feeding condition (only for the individuals that laid eggs during that period, $n=44$ ). ANOVA was performed to analyze the significance of the regression models. One-way ANOVA was performed to analyze the percentage of mature ovarioles per female, the total number of eggs laid during the last $24 \mathrm{~h}$ of each feeding condition, and the percent asymmetry of the numbers of mature ovarioles or oosorptive ovarioles, because the variances were not significantly different among the treatments (O'Brien's unequal variance test: $\mathrm{P}=0.5790, \mathrm{P}=0.4217, \mathrm{P}=$ 0.5790 , and $\mathrm{P}=0.6864$, respectively). A Kruskal-Wallis nonparametric test was used to analyze the percentage of oosorptive ovarioles per female and the percentage of weight change because the variances of the values were significantly different among the treatments (O'Brien's unequal variance test: $\mathrm{P}<0.05$ and $\mathrm{P}<0.05$, respectively). One-way ANOVA was also performed to analyze the number of ovarioles of differing stages of development per female for Condition 1 because the variances of the values were not significantly different among the stages (O'Brien's unequal variance test: $\mathrm{P}=0.2763$ ). A Kruskal-Wallis nonparametric test was used to analyze the number of ovarioles per female and the number of oosorptive ovarioles per female under the different conditions (i.e., the number of ovarioles per female in conditions 2,3 , and 4 ; the number of oosorptive ovarioles per female in conditions $1,2,3$, and 4) because the variances of the values were significantly different among the stages (O'Brien's unequal variance test: number of ovarioles in condition 2, $\mathrm{P}<0.0001$; condition $3, \mathrm{P}<0.0001$; condition $4, \mathrm{P}<$ 0.0001 ; number of oosorptive ovarioles in condition $1, \mathrm{P}<0.05$; condition $2, \mathrm{P}<0.001$; condition $3, \mathrm{P}<0.01$; condition $4, \mathrm{P}<$ 0.0001 , respectively). The percentage of oosorptive individuals was analyzed by a Chi-square test for the number of beetles in each category. Linear regression analysis was used to analyze the relationship between the percentage of weight change and the number of eggs laid during the last $24 \mathrm{~h}$ of each condition, between body length and the percent asymmetry of the numbers of mature ovarioles in the right and left ovaries, and between body length and the percent asymmetry of the numbers of oosorptive ovarioles in the right and left ovaries. All the percentage data were below $30 \%$ or above $70 \%$ and were therefore arcsine transformed (Sokal \& Rohlf, 1980). For all statistical analyses, JMP Discovery Software (SAS Institute, 2000) was used. SuperANOVA software was used to run one-way ANOVAs with Scheffé's range test (Abacus Concepts, 1989).
TABLE 1. The results of two-factor regression analysis for number of ovarioles vs. body length and body weight.

\begin{tabular}{lcrcc}
\hline Source & Source & \multicolumn{1}{c}{ SS } & F-ratio & $P$ \\
\hline body length & 1 & 0.082 & 0.001 & 0.9702 \\
body weight* & 1 & 0.005 & 0.000 & 0.9924 \\
body length $\times$ body weight & 1 & 50.734 & 0.874 & 0.3540 \\
residual & 56 & 3251.950 & &
\end{tabular}

* Body weight before the experiment, i.e., that at natural conditions.

\section{RESULTS}

\section{Ovarian development and oosorption}

Body length and body weight did not significantly affect the number of ovarioles in the female beetles (ANOVA for the whole regression model: $F_{3,56}=0.354$, $\mathrm{P}=0.7863$ ) (Table 1). A significant difference in the percentage of oosorptive individuals was observed among the conditions $\left(\chi^{2}\right.$-test, condition 1 vs. condition 2,3 , and 4 combined: $\mathrm{df}=1, \chi^{2}=18.519, \mathrm{P}=0.001$ ) (Fig. 3 ). The percentage of oosorptive individuals in the fully fed condition (condition 1) was significantly lower than that in any of the starvation conditions (conditions 2,3 , or 4) ( $\chi^{2}$-test: condition 1 vs. condition 2 ; $\mathrm{df}=1, \chi^{2}=8.889$, $\mathrm{P}=0.029$, condition 1 vs. condition $3 ; \mathrm{df}=1, \chi^{2}=$ 15.000, $\mathrm{P}=0.001$, condition 1 vs. condition 4 ; $\mathrm{df}=1$, $\chi^{2}=6.652, \mathrm{P}=0.0099$, respectively) (Fig. 3). However, no significant differences were observed among the starvation and re-fed conditions $\left(\chi^{2}\right.$-test: condition 2 vs. condition $3 ; \mathrm{df}=1, \chi^{2}=2.143, \mathrm{P}=0.1432$, condition 2 vs. condition $4 ; \mathrm{df}=1, \chi^{2}=0.240, \mathrm{P}=0.6242$, condition 3 vs. condition 4 ; $\mathrm{df}=1, \chi^{2}=3.333, \mathrm{P}=0.0679$, respectively) (Fig. 3).

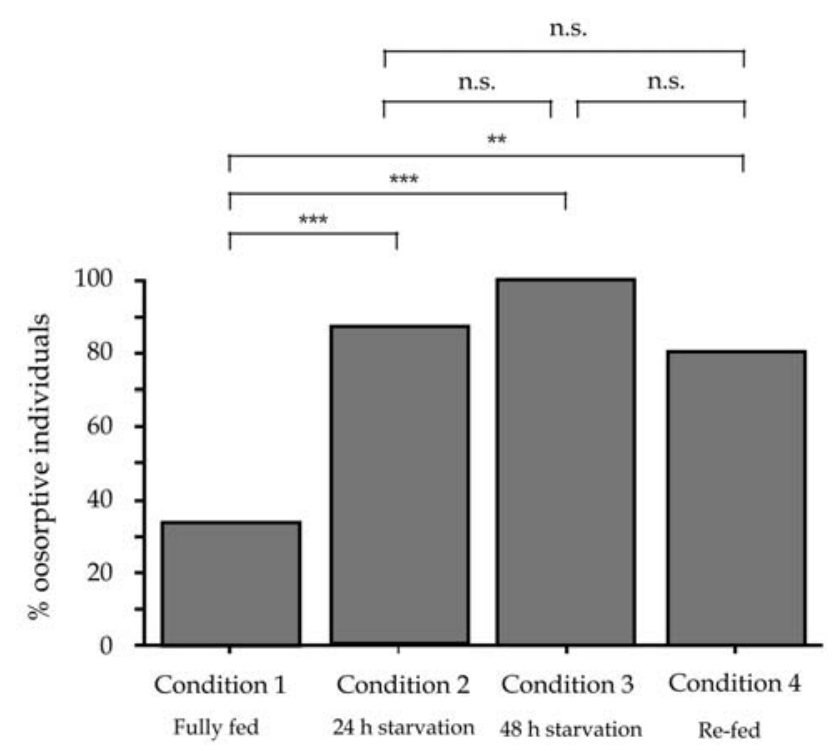

Fig. 3. The percentage of oosorptive individuals for the four feeding conditions. A double asterisk $(* *)$, a triple asterisk $(* * *)$, a quadruple asterisks $(* * * *)$, and n.s. indicate statistical difference at $\mathrm{P}=0.01, \mathrm{P}=0.001, \mathrm{P}=0.0001$, and $\mathrm{P}>0.05$ level of significance from $\chi^{2}$-test for number of individuals. 

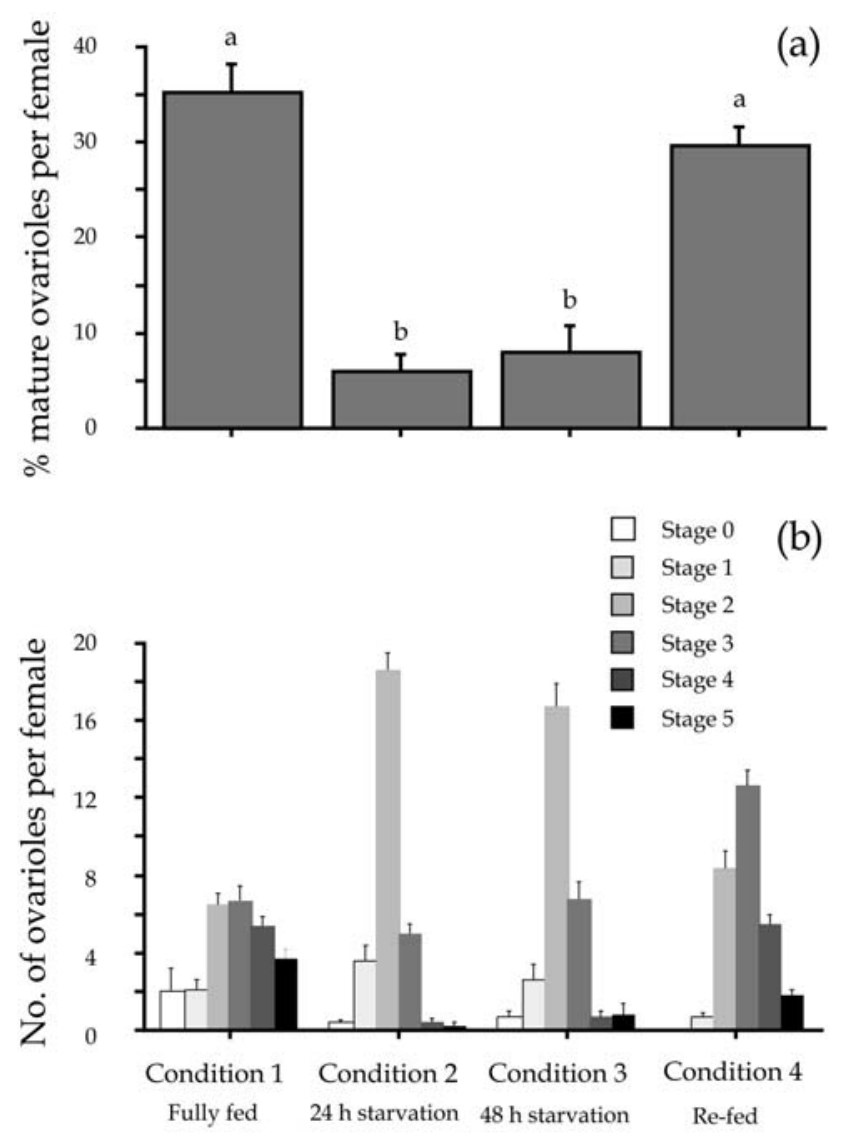

Fig. 4. (a) The percentage of mature ovarioles per female for the four feeding conditions. Vertical lines indicate S.E. Different letters indicate statistical difference at $\mathrm{P}=0.05$ level of significance from Scheffe's range test. (b) Number of ovarioles in each stages (six stages see Fig. 1) for the four feeding conditions. Vertical lines indicate S.E.

A significant difference in the percentage of mature ovarioles per female was observed among the conditions (one-way ANOVA: $\mathrm{F}_{3,56}=36.785, \mathrm{P}=0.0001$ ) (Fig. 4a). The percentage of mature ovarioles per female in the fully fed condition was significantly larger than that after 24 or $48 \mathrm{~h}$ of starvation (Scheffe's range test: $\mathrm{P}<0.05, \mathrm{P}<$ 0.05 , respectively), but not significantly different from that of the re-fed females (Scheffe's range test: $\mathrm{P}>0.05$ ) (Fig. 4a). There was a significant difference in the number of ovarioles per female in each condition; the number of stage 2 ovarioles was much larger than the number of stage $0,1,3,4$, or 5 ovarioles in the starved conditions ( 2 and 3 ), whereas this difference was small in the fully fed or re-fed conditions ( 1 and 4 , respectively) (condition 1; one-way ANOVA: $\mathrm{F}_{5,174}=8.209, \mathrm{P}=$ 0.0001, condition 2, 3, and 4; Kruskal-Wallis test: $\mathrm{df}=5$, $\chi^{2}=132.942, \mathrm{P}<0.0001 ; \mathrm{df}=5, \chi^{2}=115.689, \mathrm{P}<$ 0.0001 ; df $=5, \chi^{2}=138.988, \mathrm{P}<0.0001$, respectively) (Fig. 4b).

A significant difference was observed in the percentage of oosorptive ovarioles per female among the conditions (Kruskal-Wallis test: $\mathrm{df}=3, \chi^{2}=18.067, \mathrm{P}=0.0004$ ) (Fig. 5a). The percentage of oosorptive ovarioles per female in the fully fed condition was significantly lower
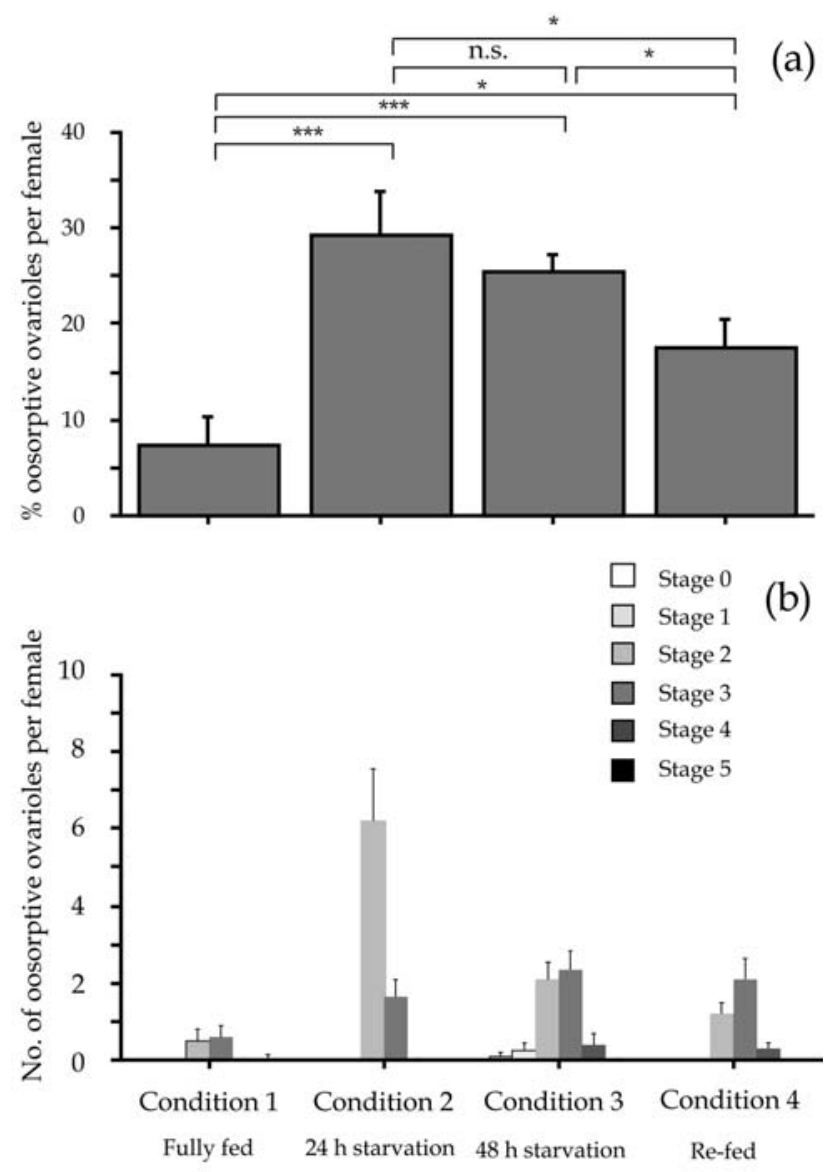

Fig. 5. (a) The percentage of oosorptive ovarioles per female for the four feeding conditions. Vertical lines indicate S.E. Asterisks $(*)$, triple asterisks $(* * *)$, and n.s. indicate statistical difference at $\mathrm{P}=0.05, \mathrm{P}=0.001$, and $\mathrm{P}>0.05$ level of significance from Kruskal-Wallis nonparametric test. (b) Number of oosorptive ovarioles per female in each stage for the four feeding conditions. Vertical lines indicate S.E.

than that in either of the starvation conditions or the re-fed condition (2, 3, and 4, respectively) (KruskalWallis test: condition 1 vs. condition 2 ; df $=1, \chi^{2}=$ $10.615, \mathrm{P}=0.0011$, condition 1 vs. condition $3 ; \mathrm{df}=1$, $\chi^{2}=13.056, \mathrm{P}=0.0003$, condition 1 vs. condition 4; $\mathrm{df}=1, \chi^{2}=4.774, \mathrm{P}=0.0289$ ) (Fig. 5a). Furthermore, a significant difference was observed between 24 -h starvation and 24-h starvation followed by $24-\mathrm{h}$ re-feeding (Kruskal-Wallis test: $\mathrm{df}=1, \chi^{2}=4.321, \mathrm{P}=0.0376$ ), as well as between 48-h starvation and re-fed (KruskalWallis test: $\mathrm{df}=1, \chi^{2}=4.051, \mathrm{P}=0.0442$ ) (Fig. 5a). However, no significant difference in the percentage of oosorptive ovarioles per female was observed between the two starvation conditions (Kruskal-Wallis test: $\mathrm{df}=1$, $\chi^{2}=0.469, \mathrm{P}=0.4936$ ) (Fig. 5a). The number of oosorptive ovarioles per female was significantly different in each condition, although the oosorptive ovarioles were observed mainly at stages 2 and 3 in all conditions (conditions 1, 2, 3, and 4; Kruskal-Wallis test: $\mathrm{df}=5, \chi^{2}=$ 11.239, $\mathrm{P}<0.05 ; \mathrm{df}=5, \chi^{2}=72.859, \mathrm{P}<0.0001 ; \mathrm{df}=5$, 
TABLE 2. The results of three-factor regression analysis for the number of eggs laid during the last $24 \mathrm{~h} *$ vs. body length, body weight, and number of ovarioles.

\begin{tabular}{lcrrr}
\hline Source & df & \multicolumn{1}{c}{ SS } & F-ratio & $P$ \\
\hline body length & 1 & 427.306 & 4.249 & 0.0462 \\
body weight** & 1 & 2217.812 & 22.049 & $<0.0001$ \\
number of ovarioles & 1 & 519.372 & 5.164 & 0.0288 \\
$\begin{array}{l}\text { body length } \times \text { body weight** } \\
\text { body weight** } \times\end{array}$ & 1 & 41.723 & 0.415 & 0.5234 \\
$\quad \begin{array}{l}\text { number of ovarioles } \\
\text { number of ovarioles } \times\end{array}$ & 1 & 386.650 & 3.844 & 0.0573 \\
$\quad$ body length & 1 & 580.942 & 5.776 & 0.0212 \\
residual & 38 & 9769.911 & & \\
\hline
\end{tabular}

* Data for the individuals that laid eggs during the last $24 \mathrm{~h}$ were only analyzed $(n=45)$.

** Body weight before the experiment, i.e., that at natural conditions.

$\chi^{2}=61.589, \mathrm{P}<0.0001 ; \mathrm{df}=5, \chi^{2}=54.795, \mathrm{P}<0.0001$, respectively) (Fig 5b).

\section{Factors affecting clutch size}

Body length, initial body weight, and the number of ovarioles were significant factors affecting the number of eggs laid during the last $24 \mathrm{~h}$ in each condition (Table 2). The interaction between the number of ovarioles and the body length also significantly affected the number of eggs (Table 2). Furthermore, the interaction between body weight and the number of ovarioles was marginally significant in affecting the number of eggs (Table 2). However, the effect of the interaction between body length and body weight on number of eggs was not significant (Table 2). The $R^{2}$ value of this model (ANOVA for the whole regression model: $\left.\mathrm{F}_{6,38}=9.855, \mathrm{P}<0.0001\right)$ was 0.547 , explaining $54.7 \%$ of the total variance of the number of eggs in each condition.

The total number of eggs was significantly different among the conditions (one-way ANOVA: $F_{3,56}=3.848$, $\mathrm{P}=0.0142$ ) (Fig. 6). The total number of eggs laid after re-feeding was significantly greater than that after the 48-h starvation (Scheffé's range test: $\mathrm{P}<0.05$ ), whereas there was no significant difference between the total

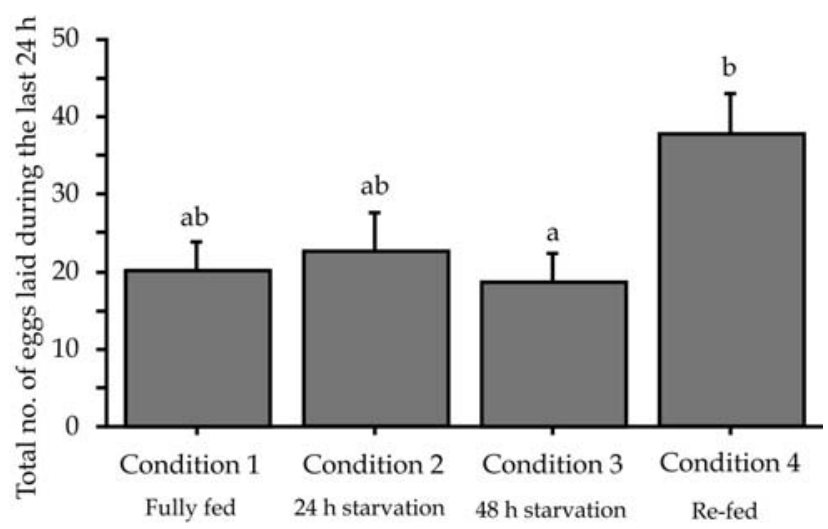

Fig. 6. Total number of eggs laid during the last $24 \mathrm{~h}$ for the four feeding conditions. Vertical lines indicate S.E. Different letters indicate statistical difference at $\mathrm{P}=0.05$ level of significance from Scheffe's range test.

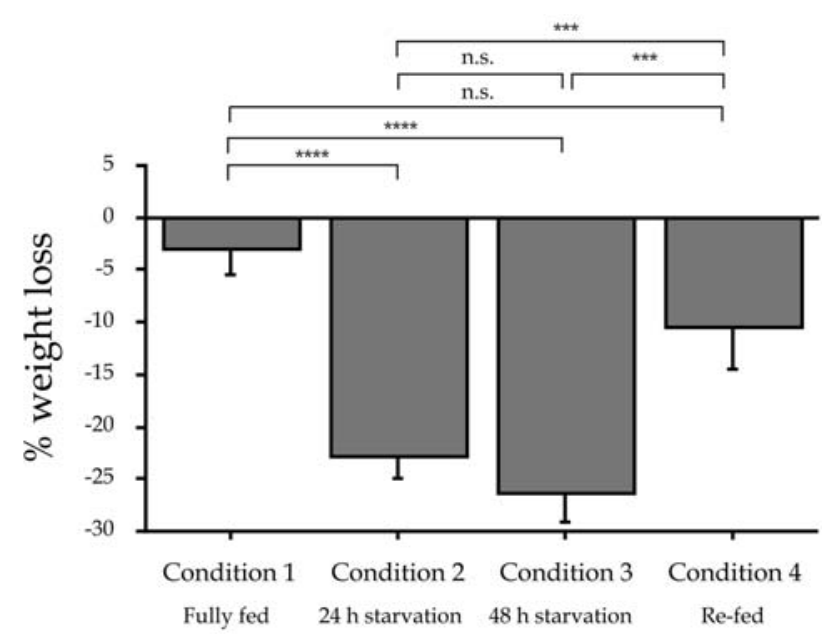

Fig. 7. The percentage of weight loss for the four feeding conditions. Triple asterisks $(* * *)$, quadruple asterisks $(* * * *)$, and n.s. indicate statistical difference at $\mathrm{P}=0.001, \mathrm{P}=0.0001$, and $\mathrm{P}>0.05$ level of significance from Kruskal-Wallis nonparametric test.

number of eggs in the fully fed and the re-fed conditions or in the 24-h starvation and re-feeding condition (Scheffé's range test: $\mathrm{P}>0.05, \mathrm{P}>0.05$, respectively) (Fig. 6).

\section{Weight loss}

The percentage weight loss differed significantly among the conditions (Kruskal-Wallis test: $\mathrm{df}=3, \chi^{2}=$ 46.526, $\mathrm{P}=0.001$ ) (Fig. 7). The percentage weight loss of fully fed beetles was significantly lower than that of beetles in either of the starvation conditions (Kruskal-Wallis test: condition 1 vs. condition $2, \mathrm{df}=1, \chi^{2}=35.992, \mathrm{P}<$ 0.0001 ; condition 1 vs. condition $3, \mathrm{df}=1, \chi^{2}=18.417$, $\mathrm{P}<0.0001$, respectively) (Fig. 7). Furthermore, the percentage weight loss of re-fed beetles was significantly

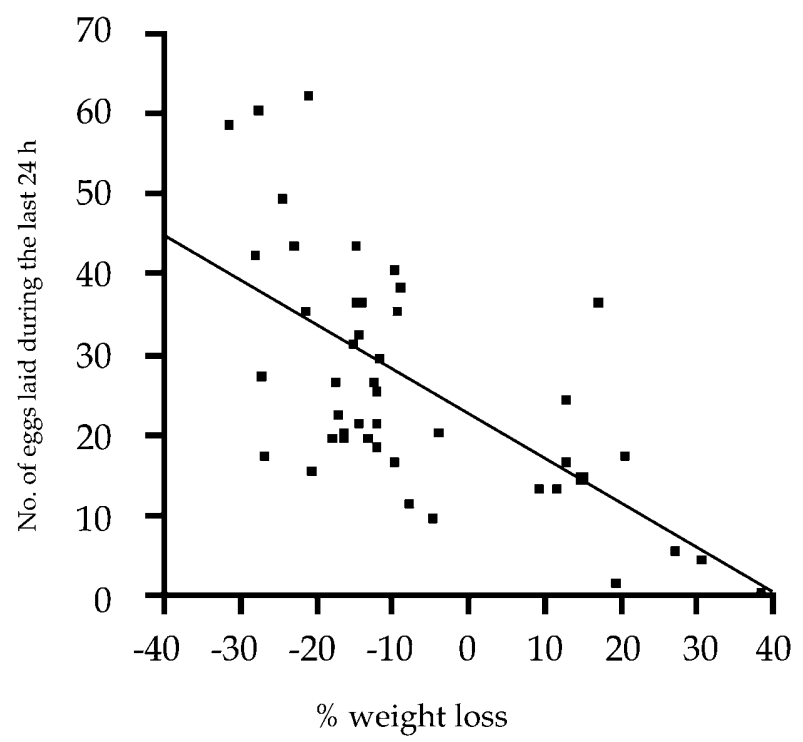

Fig. 8. The relationship between the percentage of weight loss and number of eggs laid during the last $24 \mathrm{~h}$. 

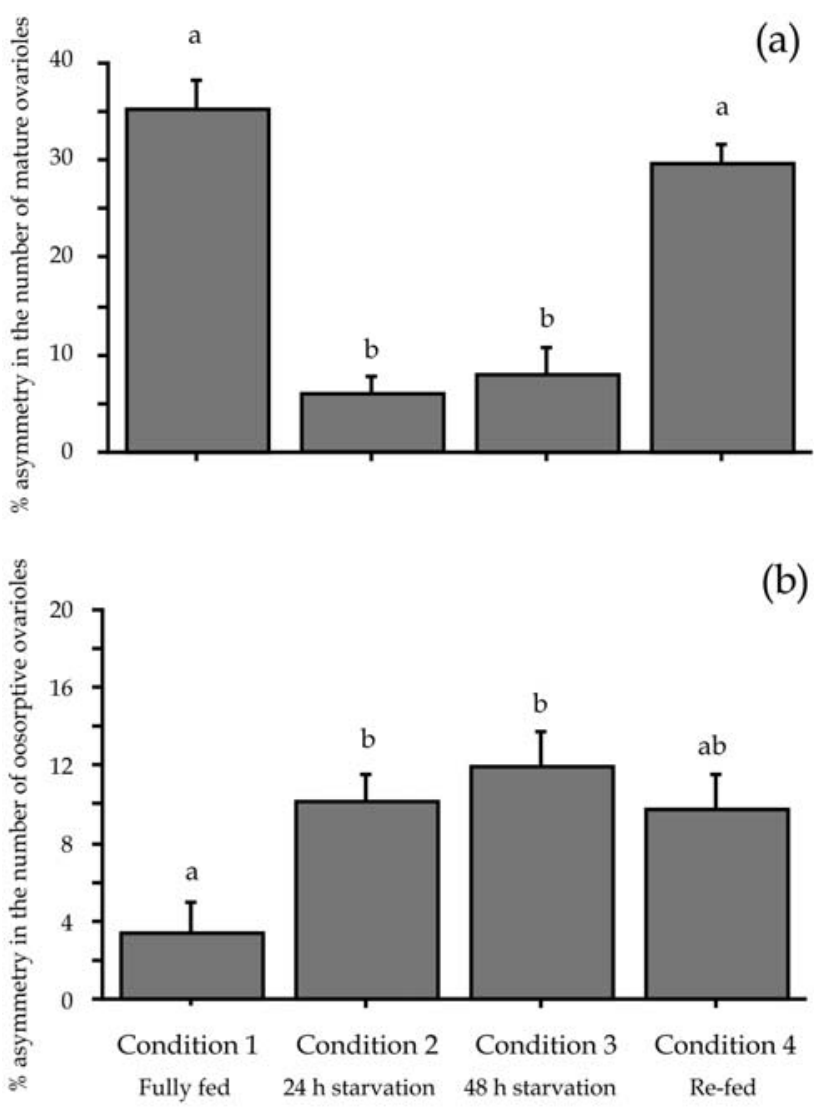

Fig. 9. (a) The percentage of asymmetry in the number of mature ovarioles per female for the four feeding conditions. Vertical lines indicate S.E. Different letters indicate statistical difference at $\mathrm{P}=0.05$ level of significance from Scheffe's range test. (b) The percentage of asymmetry in the number of oosorptive ovarioles per female at the four feeding conditions. Vertical lines indicate S.E. Different letters indicate statistical difference at $\mathrm{P}=0.05$ level of significance from Scheffe's range test.

lower than that of beetles in either of the starvation conditions (Kruskal-Wallis test: condition 4 vs. condition 2, $\mathrm{df}=1, \chi^{2}=11.139, \mathrm{P}=0.0008$; condition 4 vs. condition 3 , df $=1, \chi^{2}=8.310, \mathrm{P}=0.0039$, respectively) (Fig. 7). However, no significant difference in percentage weight loss was observed between fully fed and re-fed beetles (Kruskal-Wallis test: $\mathrm{df}=1, \chi^{2}=2.443, \mathrm{P}=0.1181$ ), nor between the two starvation conditions (Kruskal-Wallis test: $\mathrm{df}=1, \chi^{2}=0.432, \mathrm{P}=0.511$ ) (Fig. 7).

There was a significant correlation between the percentage weight loss and the number of eggs laid during the last $24 \mathrm{~h}\left(R^{2}=0.415, \mathrm{~F}_{1,43}=30.451, \mathrm{P}<0.0001\right)$ (Fig. $8)$.

\section{Asymmetry of ovariole maturity and oosorption in the right and left ovaries}

The percent asymmetry in the numbers of mature ovarioles in the right and left ovaries was significantly different among the conditions (one-way ANOVA: $\mathrm{F}_{3,56}=$ 36.785, P $<0.0001$ ) (Fig. 9a). Fully fed and re-fed beetles had significantly greater percent asymmetry of mature ovarioles than did beetles in either starvation condition (Scheffé's range test: $\mathrm{P}<0.05, \mathrm{P}<0.05$, respectively)

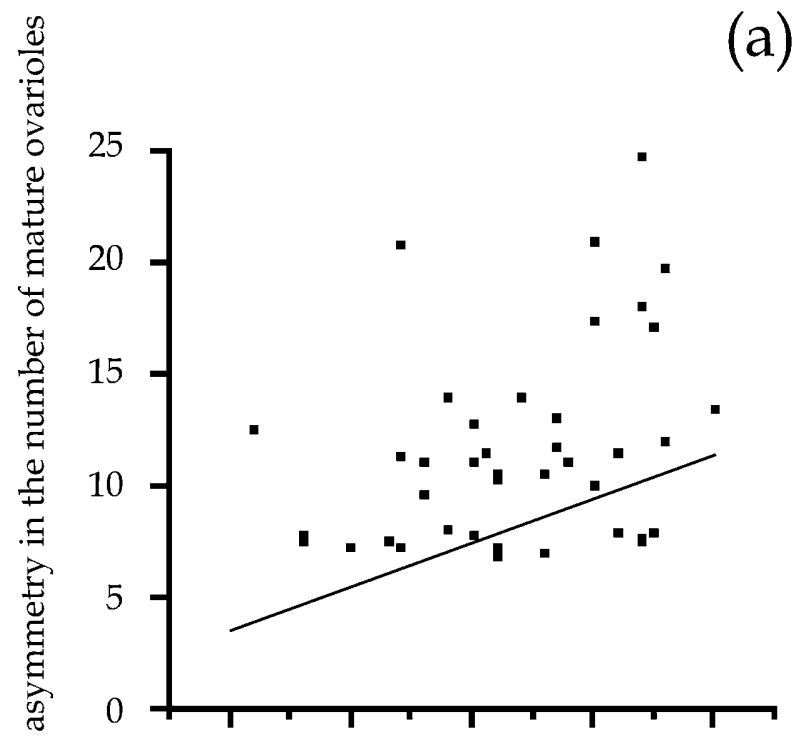

o
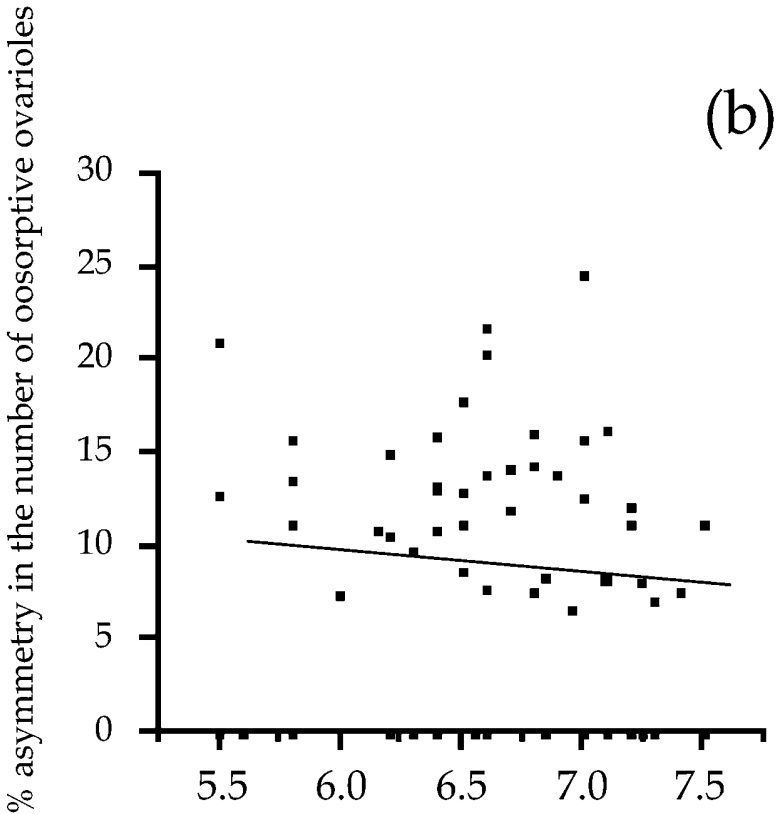

Body length (mm)

Fig. 10. (a) The relationship between body length and the percentage of asymmetry in the number of mature ovarioles. (b) The relationship between body length and the percentage of asymmetry in the number of oosorptive ovarioles.

(Fig. 9a). The percent asymmetry in the numbers of oosorptive ovarioles in the right and left ovaries was also significantly different among the conditions (one-way ANOVA: $F_{3,56}=5.284, P=0.0028$ ) (Fig. 9b). The percent asymmetry in the numbers of oosorptive ovarioles was significantly smaller in fully fed beetles than in beetles in either starvation condition (Scheffé's range test: $\mathrm{P}<0.05$, $\mathrm{P}<0.05$, respectively), although there was no significant difference between the fully fed and re-fed conditions (Scheffé's range test: $\mathrm{P}>0.05$ ) (Fig. 9b). 
There was a weak but significant correlation between body length and the percent asymmetry in the numbers of mature ovarioles in the right and left ovaries (linear regression: $R^{2}=0.096, \mathrm{~F}_{1,58}=6.135, \mathrm{P}=0.0162$ ) (Fig. $10 \mathrm{a})$, but no significant correlation between body length and the percent asymmetry in the numbers of oosorptive ovarioles in the right and left ovaries (linear regression: $\mathrm{F}_{1,58}=0.419, \mathrm{P}=0.5198$ ) (Fig. 10b).

\section{DISCUSSION}

In herbivorous ladybird beetles of the genus Henosepilachna (Epilachna), oosorption occurs in adults during the prediapause period, induced by short photoperiods (Maki et al., 1964; Kono, 1980) and by temperature cues (Maki \& Kurihara, 1965). Oosorption is also induced by nutritional deficiencies caused by the quality or quantity of available food, and especially by starvation (Kurihara, 1975, 1981; Kono, 1979). However, oosorption is less well documented in the case of predatory ladybird beetles.

In Coccinella septempunctata, it is known that the number of ovarioles is positively correlated with body size (Rhamhalinghan, 1985; Dixon \& Guo, 1993). Rhamhalinghan (1985) showed that variation in the number of ovarioles was a result of larval starvation, and he observed seasonal variations in the number of ovarioles. Generally, ovarian development starts during late embryogenesis and proceeds throughout the larval and pupal stages, although it is species-specific and depends on the life cycle and behavior of the larval and adult stages (Büning, 1994). Body length, initial body weight (body weight at the time of collection from natural conditions), and the interaction between the body weight and body length were not significant factors affecting the number of ovarioles in Harmonia axyridis females (Table 1). This implies that the number of ovarioles in $H$. axyridis is genetically determined regardless of the larval feeding conditions.

The results of this study showed that the percentage of oosorptive individuals and the percentage of oosorptive ovarioles per female in fully fed beetles were significantly lower than those in beetles subjected to less suitable conditions (Fig. 3). These results suggest that starvation for up to $24 \mathrm{~h}$ is an important factor for the induction of oosorption in $H$. axyridis. No significant difference in the proportion of oosorptive individuals was observed among beetles starved for $24 \mathrm{~h}$ or more (conditions 2, 3, and 4) (Fig. 3), indicating that starvation for longer than $24 \mathrm{~h}$ did not increase, and re-feeding for $24 \mathrm{~h}$ after a 24 -h starvation did not decrease, the proportion of oosorptive individuals. However, the percentage of oosorptive ovarioles per female in re-fed beetles was significantly lower than that in beetles under either starvation condition (Fig. 5a), suggesting that $24 \mathrm{~h}$ of abundant food after a 24-h fast can promote the re-development of ovarioles. The number of stage 2 ovarioles in the re-fed females tended to be lower than that found in either starvation condition (Fig 5b); thus, the re-development of oosorptive ovarioles might occur especially in ovarioles at earlier stages of development.

Individual oosorptive beetles were constantly present in the natural population of $H$. axyridis (33.33\%) (Fig. 3), implying that $H$. axyridis adults often experience starvation even under natural conditions in early spring. Ovarian degeneration (i.e., a kind of oosorption) in the late reproductive season has been known in Henosepilachna complex (Katakura, 1976; Katakura et al., 1978; Ohgushi \& Sawada, 1985; Ohgushi, 1996), which increases female survival to the following reproductive season at the next year (Ohgushi \& Sawada, 1985). The ovarian degeneration observed in the Henosepilachna complex may be regarded as a pre-hibernation behavior. In fact, the ovarian oosorption is usually not observed at the early and middle reproductive seasons in $H$. niponica (Ohgushi \& Sawada, 1985). These results suggest that the ovarian oosorption observed in this study is different from the ovarian degeneration in the Henosepilachna species; the ovarian oosorption observed in this study on $H$. axyridis is influenced only by a food condition, while that in the Henosepilachna complex may be caused by the seasonal change of environments, e.g., the change of photoperiod, temperature, and available resource conditions.

$H$. axyridis adults, which have highly developed prey searching and reproductive abilities, maintain a stable population in heterogeneous and temporal habitats by means of their resource-tracking mechanisms (Osawa, 2000). The current study showed that the percentage of mature ovarioles per female in fully fed beetles was significantly greater than that of starved beetles, but not significantly different from that of re-fed beetles (Fig. 4a). Notwithstanding, the percentage of oosorptive ovarioles per female in the fully fed condition was significantly lower than in any other condition (Fig. 5a). These findings suggest that the ovarian development was resumed when beetles were re-fed for $24 \mathrm{~h}$ after a 24 -h starvation; however, the level of oosorption was not fully restored by this brief period of re-feeding. It takes approximately 15 days for an oocyte to develop and approximately 10 days for complete oosorption at a starved condition in the herbivorous ladybird beetle E. vigintioctomaculata (Kurihara, 1975). The results of the current study suggest that (1) ovarian development and oosorption in response to available food conditions are much faster in the predatory ladybird beetle $H$. axyridis than in the herbivorous ladybird beetles and (2) the re-development of oocytes in ovarioles during $24 \mathrm{~h}$ of re-feeding after $24 \mathrm{~h}$ of starvation occurs more quickly than oosorption. These characterstics at ovarian development and oosorption in $H$. axyridis may result in oviposition being concentrated in favorable habitats (Osawa, 2000).

This study showed that the total number of eggs laid during the last $24 \mathrm{~h}$ in each condition varied significantly: the number of eggs laid in re-fed females was significantly larger than the number laid in the 48-h starved females, whereas no significant difference was found between the fully fed and re-fed females, or between 24-h starved and the re-fed females (Fig. 6). In the two starva- 
tion conditions, some females oviposited few eggs regardless of the food supply. Based on these results, $24 \mathrm{~h}$ of starvation and $24 \mathrm{~h}$ of abundant feeding are not determining factors for the total number of eggs laid by $H$. axyridis; rather, the total amount of food available over a more extended period might be more critical. This implies that the re-development of oosorptive ovarioles occurs within $24 \mathrm{~h}$ at the fully fed females. The increase in the ratio of ovarioles at stage 3,4 , and 5 (Fig. 4b) and the decrease in the ratio of oosorptive ovarioles at stage 2 (Fig. 5b) in the re-fed females, compared with these ratios in the starvation conditions, also supports this observation.

The weight loss in the fully fed females was significantly lower than that in the two starved females, but similar to that in the re-fed females (Fig. 7). These results suggest that (1) a rapid decrease in weight occurred due to starvation and (2) weight was rapidly regained when beetles had access to abundant food. The absence of a significant difference in weight loss between fully fed and re-fed beetles indicates that the recovery of lost weight occurred within $24 \mathrm{~h}$ after a 24-h starvation; thus, the duration of starvation might determine the speed of weight recovery. There was also no significant difference in weight loss between females at two starved conditions, which suggests that the duration of starvation modifies the pattern of oosorption. Starvation for a shorter period (i.e., $24 \mathrm{~h}$ ) caused oosorption of mainly intermediate stage ovarioles (i.e., stage 2 and 3), whereas a longer period of starvation (i.e., $48 \mathrm{~h}$ ) induced oosorption at a wide range of ovariole stages (Fig. 5b). This pattern of oosorption might buffer the degree of weight loss during longer periods of starvation.

The mean size of clutch in this study was $20.13 \pm 2.25$ eggs (mean \pm S.E., $n=60$ ), which corresponds to a loss of only $0.94 \%$ of body weight (regression equation: $\mathrm{Y}=$ $19.23-0.858 \mathrm{X}$, where $\mathrm{X}$ is the percentage weight loss (not arcsine-transformed) and $\mathrm{Y}$ is the number of eggs laid during the last $24 \mathrm{~h}$ ) (Fig. 8). This indicates that the weight of the eggs laid by a $H$. axyridis female was almost the same as the weight of the digested food. Therefore, the realized volume of the eggs laid may be directly determined by the amount of food digested.

Asymmetric ovarian development and oosorption have already been reported in E. vigintioctomaculata (e.g., Kurihara, 1975). Furthermore, there is variation in ovarian development and oosorption between the inner and outer ovarioles within ovaries (Kurihara, 1975). However, the biological implications of asymmetric ovarian development and oosorption have not been examined. In the current study, the percent asymmetry of the number of mature ovarioles in fully fed and re-fed beetles was significantly greater than that in starved beetles (Fig. 9a), indicating that ovariole development in the right and left ovaries is asymmetric. This rhythmic development of the ovary might be an important strategy for oviposition in resource-tracking predators such as $H$. axyridis that forage for intermittent prey, because selective provision of maturing ovarioles in the right or left ovary with digested nutrients is thought to be adaptive for a rapid oviposition response at heterogeneous, fluctuating, and unpredictable resource conditions. Furthermore, this study showed that the percent asymmetry of the number of oosorptive ovarioles in the fully fed females was significantly smaller than that in either of the starved females, but not significantly different from the re-fed females (Fig. 9b), indicating that oosorption is also asymmetric. Asymmetric oosorption might be caused by asymmetric ovariole development in the ovary.

The results of this study indicate a weak but significant correlation between body length and the percent asymmetry of the numbers of mature ovarioles in the right and left ovaries (Fig. 10a), implying that the ability to control rhythmic and asymmetric development of ovarioles in the ovary might be determined by body size, mainly owing to the large energetic cost of ovarian development. However, no significant correlation existed between body length and the percent asymmetry of the numbers of oosorptive ovarioles in the right and left ovaries (Fig. $10 \mathrm{~b}$ ), suggesting that the ability to control asymmetric oosorption is not influenced by body size, perhaps because of its relatively low energetic cost.

Taken together, the results obtained here suggest an additional role of the ovary in $H$. axyridis: apart from egg production, it serves as a kind of energy storage system that favors reproductive success. Immediate ovarian development in satiation and rapid oosorption in starvation would be an adaptive ovipositional and survival strategy for female adults of $H$. axyridis to cope with heterogeneous and fluctuating resource conditions.

ACKNOWLEDGEMENTS. I am indebted to M. Kurihara, Iwate University, for helpful comments and information at the beginning of this study. Thanks are also due to H. Katakura, Hokkaido University, for his helpful comments to improve this manuscript. I am also indebted to E. Kuno, H. Takeda, and T. Ohgushi, Kyoto University, for their supports and encouragements during this study. This study was supported in part by a Grant-in-Aid for Science Research (No. 02954077 and 13306012 , to N. Osawa) from the Japan Society for the Promotion of Sciences, and the COE for Innovative Food and Environmental Studies Pioneered by Entomomimetic Sciences (the COE programs of the Ministry of Education, Culture, Sports, Science, and Technology of Japan).

\section{REFERENCES}

Abacus Conceps 1989: SuperANOVA Software (ver. 1.1.1.). Abacus Concepts Inc., Berkeley, CA.

Bell W.J. \& Bонм M.K. 1975: Oosorption in insect. Biol. Rev. 50: 373-396.

BüNING J. 1994: The Insect Ovary. Chapman \& Hall, London, $400 \mathrm{pp}$.

CHAPMAN R.F. 1998: The Insects - Structure and Function. 4th ed. Cambridge University Press, New York, 770 pp.

Dixon A.F.G. \& Guo Y. 1993: Egg and cluster size in ladybird beetles (Coleoptera: Coccinellidae): The direct and indirect effects of aphid abundance. Eur. J. Entomol. 90: 457-463.

ECKEBERGER K.J. 1994: Diversity of metazoan ovaries and vitellogenic mechanisms: implications for life history theory. Proc. Biol. Soc. Wash. 107: 193-218. 
KatakuRa H. 1976: Phenology of two sympatric phytophagous ladybirds of Henosepilachna vigintioctomaculata complex in and near Sapporo, northern Japan (Coleoptera: Coccinellidae). J. Fac. Sci. Hokkaido Univ. (Ser. VI, Zool.) 20: 313-328.

Katakura H., Hoshikawa K. \& Kimura T. 1978: Miscellaneous notes on the two remarkable populations of Henosepilachna vigintioctomaculata complex recently discovered in the central Honshu. New Entomol. 27: 23-27 (in Japanese, English abstr.).

Kono Y. 1979: Abnormal photoperiodic and phototactic reactions of the beetle, Epilachna vigintioctomaculata, reared on sliced potatoes. Appl. Entomol. Zool. 14: 185-192.

Kono Y. 1980: Endocrine activities and photoperiodic sensitivity during prediapause period in the phytophagous lady beetle, Epilachna vigintioctomaculata. Appl. Entomol. Zool. 15: $73-80$.

KURIHARA M. 1975: Anatomical and histological studies on the germinal vesicle in degenerating oocyte of starved females of the lady beetle, Epilachna vigintioctomaculata Motschulsky (Coleoptera, Coccinellidae). Kontyû 43: 91-105.

KURIHARA M. 1981: Fine structural change of the follicular cells during oosorption in the starved lady beetle, Epilachna vigintioctomaculata Motschulsky, with special reference to the demonstration of acid phosphatase. Kontyû 49: 65-80.

MaEta Y. \& Kurihara M. 1971: Anatomical and histological studies on the oogenesis and resorption of terminal oocytes within genus Osmia. Kontŷu 39: 138-158.

MAKI T. \& Kurihara M. 1965: Effects of temperatures on reversibility of ovarian development in the lady beetle, Epilachna vigintioctomaculata Motschulsky. J. Fac. Agric. Iwate Univ. 7: 167-172.

MaKi T., Kurihara M. \& ANDo Y. 1964: On the reversibility of ovarian development of the lady beetle Epilachna vigintioc- tomaculata Motschulsky by the photoperiodic effects. J. Fac. Agric. Iwate Univ. 7: 7-17.

Овата S. 1988: Mating refusal and its significance in females of the ladybird beetle, Harmonia axyridis. Physiol. Entomol. 13: 193-199.

OHgushi T. 1996: A reproductive tradeoff in an herbivorous lady beetle: egg resorption and female survival. Oecologia 106: $345-351$.

Ohgushi T. \& Sawada H. 1985: Population equilibrium with respect to available food resource and its behavioural basis in an herbivorous lady beetle Henosepilachna niponica. J. Anim. Ecol. 54: 781-796.

Osawa N. 2000: Population field studies on the aphidophagous ladybird beetle Harmonia axyridis (Coleoptera: Coccinellidae): resource tracking and population characteristics. Popul. Ecol. 42: 115-127.

Papaj D.R. 2000: Ovarian dynamics and host use. Annu. Rev. Entomol. 45: 423-448.

Perez-Mendoza J., Thorne J.E. \& Baker J.E. 2004: Ovarian physiology and age-grading in the rice weevil, Sitophilus oryzae (Coleoptera: Curculionidae). J. Stor. Prod. Res. 40: 179-196.

RHAMHALINGHAN M. 1985: Intraspecific variations in ovariole number/ovary in Coccinella septempunctata L. (Coleoptera: Coccinellidae). Ind. Zool. 9: 91-97.

SAS Institute 2000: JMP Statistical Discovery Software (ver. 4). SAS Institute Inc., Cary, NC.

Sokal R.R. \& Rohlf F.J. 1980: Biometry. 2nd ed. W.H. Freeman, New York, 859 pp.

WILDE DE J. 1964: Reproduction-endocrine control. In: Rockstein M.(ed.): The Physiology of Insecta. Vol. 1. Academic Press, New York, pp. 59-90.

Received September 10, 2004; revised and accepted March 4, 2005 